\title{
Gastric carcinoma and renal cell carcinoma as an atypical presentation of multiple primary malignancies: a case report and review of the literature
}

\author{
J. A. Martín-Pérez ${ }^{1,4^{*}}$ (D, C. Torres-Silva ${ }^{2,4}$, R. Tenorio-Arguelles ${ }^{2,4}$, D. A. García-Corona ${ }^{2,4}$, S. Silva-González ${ }^{2,4}$, \\ J. A. Dominguez-Rodriguez ${ }^{1,4}$, I. De Alba-Cruz ${ }^{1,4}$, J. F. Nagore-Ancona ${ }^{1,4}$, J. A. González-Luna ${ }^{1,4}$ \\ and K. A. López-Bochm ${ }^{3,4}$
}

\begin{abstract}
Background: Gastric carcinoma (GC) with second primary malignancy (SPM) is the most frequent combination within the multiple primary malignancies (MPM) group. The presentation of a GC associated with a synchronized SPM in the kidney is extremely rare and unusual. This study presents a rare case of synchronous tumors, describes the main associated risk factors, and emphasizes the need to rule out SPM.

Main body: We present the case of a 63-year-old Hispanic woman with a history of smoking, weight loss, and gastrointestinal (GI) bleeding. GC was diagnosed by endoscopy, and during her workup for metastatic disease, a synchronous SPM was noted in the left kidney. The patient underwent resection of both tumors with a satisfactory postoperative course. A systematic review of the literature was performed using the Medline/PubMed, Science Direct, Scopus, and Google Scholar databases. A search of the literature yielded 13 relevant articles, in which the following main risk factors were reported: the treatment utilized, the grade and clinical stage, histopathological report, and in some cases survival. It is concluded that advanced age (> 60 years) and smoking are the main associated risk factors.

Conclusion: Gastric carcinoma is the second most frequent neoplasm of the Gl tract and the main neoplasm that presents a SPM. MPM screening is recommended in patients with gastric cancer. The clinical discovery of MPM of renal origin is rare and hence the importance of the current report.
\end{abstract}

Keywords: SPM, MPM, Synchronous, Partial gastrectomy, Radical nephrectomy, Smoking, Gastric tumor, Renal tumor, Seal ring cells, Clear cell renal carcinoma

\section{Introduction}

In 1930, Warren and Gates first described the concept of multiple primary malignancies (MPN) [1]. Subsequently, the definition of a synchronous tumor was standardized,

\footnotetext{
*Correspondence: chucho0892@gmail.com

1 Surgical Department, "General Ignacio Zaragoza" Regional Hospital,

Ejército Constitucionalista, Chinam Pac de Juárez, Calz. Ignacio Zaragoza

1711, 09220 Mexico City, MX, Mexico

Full list of author information is available at the end of the article
}

according to the time of diagnosis of the second primary malignancy (SPM), with the SPM diagnosed within a period of time no greater than 6 months after the diagnosis of the primary tumor. This definition is the one used for SPM identification in the literature review [2-7].

In the case of the presence of gastric carcinoma (GC) with SPM, the incidence is higher in Asian countries [813]. SPMs are mainly observed in the colon, followed by the breast and the lung; a malignancy in the kidney is rare [14-16]. The incidence of synchronous stomach-kidney original author(s) and the source, provide a link to the Creative Commons licence, and indicate if changes were made. The images or other third party material in this article are included in the article's Creative Commons licence, unless indicated otherwise in a credit line to the material. If material is not included in the article's Creative Commons licence and your intended use is not permitted by statutory regulation or exceeds the permitted use, you will need to obtain permission directly from the copyright holder. To view a copy of this licence, visit http://creativecommons.org/licenses/by/4.0/. The Creative Commons Public Domain Dedication waiver (http://creativeco mmons.org/publicdomain/zero/1.0/) applies to the data made available in this article, unless otherwise stated in a credit line to the data. 
tumors worldwide is around $0.13-0.42 \%$. Up to $40 \%$ are diagnosed with SPM in the early stages and 9\% are diagnosed in advanced stages [17-19].

$\mathrm{GC}$, according to reviews, is the neoplasm with the highest presence of SPM [3, 18-20]. Currently, there is no standardized study protocol for the evaluation of SPMs in GC.

The objective of this study is to present a case of synchronous renal cell carcinoma in a patient with GC, as well as to describe the associated risk factors and emphasize the need to rule out the possibility of a SPM during the clinical staging of the primary malignancy.

\section{Case report}

The patient is a 63-year-old Hispanic woman with a history of peptic ulcer disease with dyspepsia and was treated with a proton pump inhibitor (PPI). She was diagnosed with Helicobacter pylori infection and received a triple drug therapy. Subsequently she experienced weight loss of approximately $14 \mathrm{~kg}$ over 2 months $(\mathrm{BMI}=18.4$; previous weight $64 \mathrm{~kg}, \mathrm{BMI}=23.5$ ), and her dyspepsia did not improve. Colonoscopy and esophagogastroduodenoscopy (EGD) were performed and revealed a $4 \mathrm{~cm}$ pyloric ulcer and $70 \%$ pyloric stenosis; biopsies were taken at the time of the EGD. The biopsy demonstrated adenocarcinoma in signet ring cells. She was referred to the General Ignacio Zaragoza Regional Hospital Surgery Department for further evaluation. Social history was significant for an 18-pack-year smoking history. Her family history was significant for first-degree relatives with a history of cancer: one with bladder carcinoma and the other with prostate carcinoma. Her physical examination was within normal limits. Laboratory tests demonstrated normal hemoglobin and hematocrit levels, normal liver enzymes, and normal renal function; however, urinalysis was significant for both proteinuria and hematuria, and her blood type is A positive. Carbohydrate antigen (CA)125 and CA19-9 were normal. Her chest X-ray was normal for her age. A computed tomography (CT) scan of her abdomen and pelvis showed a tumor in her left kidney of approximately $140 \times 97 \times 85 \mathrm{~mm}$ with homogeneous enhancement in its upper pole. No distant metastases were evident. Surgical intervention with an exploratory laparotomy was undertaken, where a partial gastrectomy was performed with gastrojejunal anastomosis with omega of Braun reconstruction and left radical nephrectomy. Interoperative cryosections were evaluated by pathology. She had an estimated blood loss of $850 \mathrm{cc}$, with an estimated surgical time of 210 minutes. The postsurgical course was without complications. The histopathological report describes the left kidney with a size of $100 \times 80 \mathrm{~mm}$ with a tumor in the upper and middle pole of $70 \times 50 \mathrm{~mm}$. The tumor type was clear cell renal cell carcinoma with a histological grade II on the Fuhrman scale with extension beyond Gerota's capsule. The clinical stage was T4 N0 M0. The gastric tumor with dimensions of $10 \times 10 \mathrm{~mm}$ in the antrum and pylorus showed diffuse type adenocarcinoma with signet ring cells with little differentiated histological grade and pathological stage T2 No M0. The patient is currently under active surveillance with monthly monitoring by the departments of surgery and medical oncology; to date her CT scan and laboratory tests demonstrate no evidence of relapse or distant metastases.

\section{Materials and methods Inclusion criteria}

This systematic review was designed according to the Preferred Reporting Items for Systematic Reviews and Meta-Analyses (PRISMA) [21].

All articles written in English and Spanish related to cases of synchronous gastric and/or renal carcinoma were included. Exclusion criteria were articles not meeting the criteria for the definition of synchronous cancer [1].

\section{Search strategy}

The study design was developed and strictly followed by all participating authors. Identification of eligible studies was performed through a systematic literature search using Medline/PubMed, Science Direct, Scopus, and Google Scholar.

The end date for the literature search was April 1, 2020. The following keywords were used in the search algorithm: ("cancer OR tumor OR neoplasia") AND ("synchronous double primary") AND ("Gastric OR Gastric Adenocarcinoma") AND ("renal carcinoma OR kidney carcinoma). Two independent reviewers performed the literature review. The reference lists of eligible articles were manually evaluated to detect potentially relevant articles. The selection process for this article is shown in Fig. 6.

\section{Systematic review and data extraction}

The study design did not use an exclusion factor due to the scarcity of publications on the subject. After removing duplicates, two reviewers independently selected all abstracts and articles for the full-text review. Data analysis was extracted from full-text articles.

\section{Statistical analysis}

The PRISMA flowchart was generated by Cochrane RevMan software version 5.2.

The initial literature search identified 1172 articles. Of these, 1159 articles were excluded as they did not meet the review criteria, were duplicates, were not in 
the included language, were studies without data of interest, or were letters/opinions from experts. Thirteen studies were selected which met the inclusion criteria. Manual search and cross-checking of reference lists of included articles yielded no additional relevant articles. Figure 1 shows a flow diagram illustrating the identification and inclusion/exclusion processes in the study (Figs. 2, 3, 4, 5, 6).

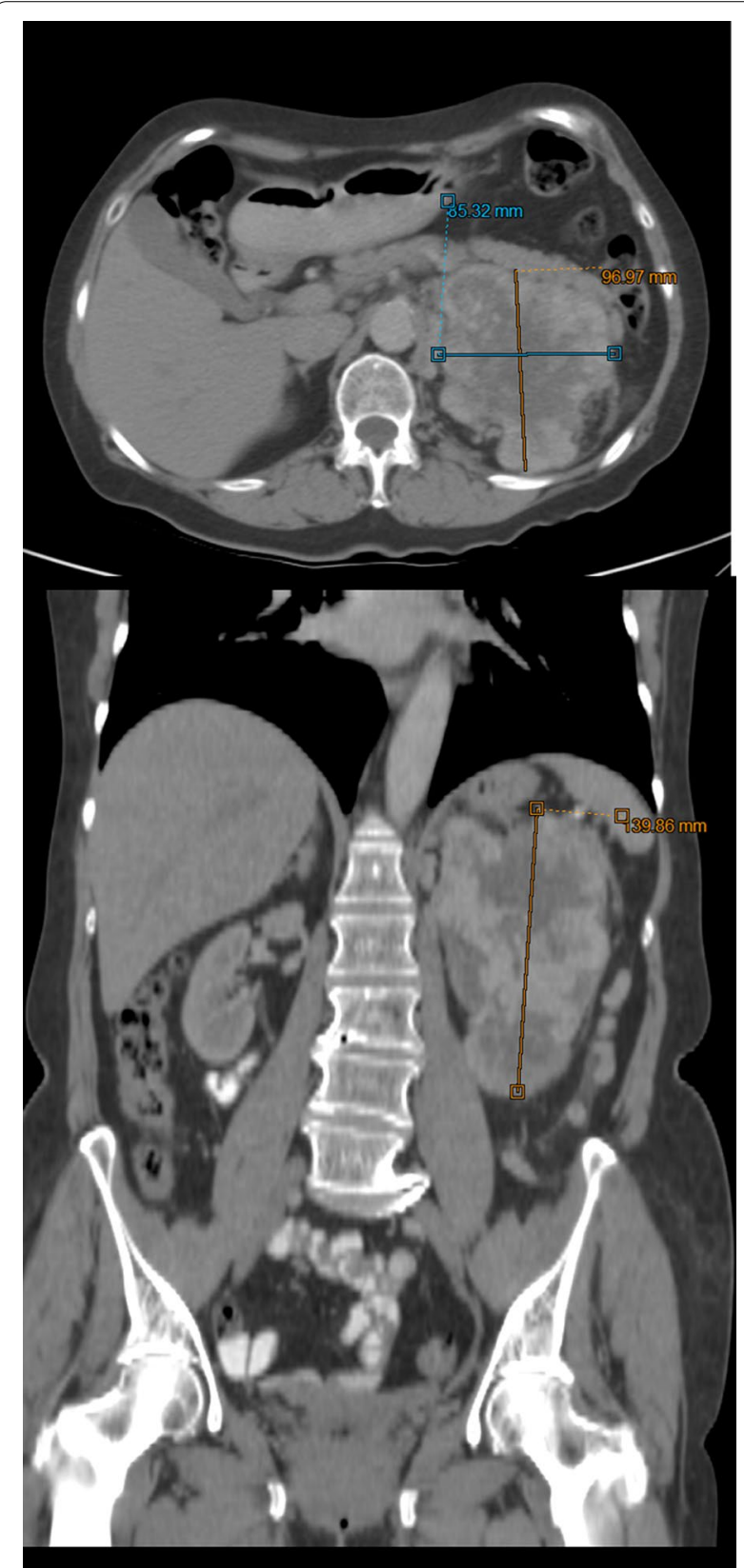

Fig 1. CT scan in which the left kidney cancer is observed with dimensions of $140 \times 97 \times 85 \mathrm{~mm}$

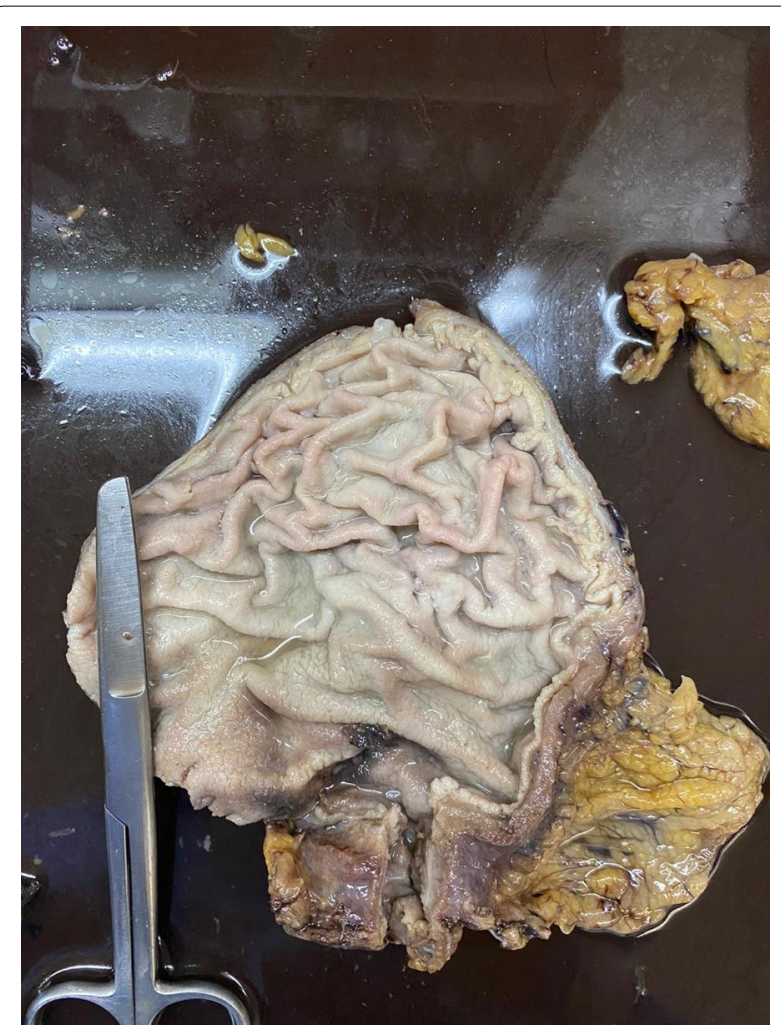

Fig 2. Product of partial gastrectomy (antrum and pylorus) that measures $100 \times 60 \times 40 \mathrm{~mm}$; the cut of this area is identified

\section{Results}

The total population studied in our review yielded 21,157 patients with GC and 1744 patients with renal carcinoma. The subgroups of patients with GC and renal carcinoma presenting with a synchronous tumor numbered 354 and 82, respectively. A total of 45 cases of synchronous tumors with GC and renal carcinoma were found in our study. Figure 7 shows, schematically, the population and how it was obtained.

Within the information search, 45 patients with a diagnosis of synchronous cancer were integrated and are described in Tables 1 and 2. However, in the studies with an epidemiological design described in Table 1 , it was not possible to collect particular data about the cases because they described patients with synchronous cases in general and not exclusively synchronous gastric cancer with kidney cancer.

Of the total number of cases reported in the literature with synchronous GC and kidney carcinoma, the highest prevalence was found in elderly patients ( $>60$ years), with males outnumbering females 2:1. The most commonly reported risk factor was smoking $[2,4,17,18,20$, 22-25]. The most frequent clinical presentations were upper or lower gastrointestinal (GI) bleeding, nonspecific 


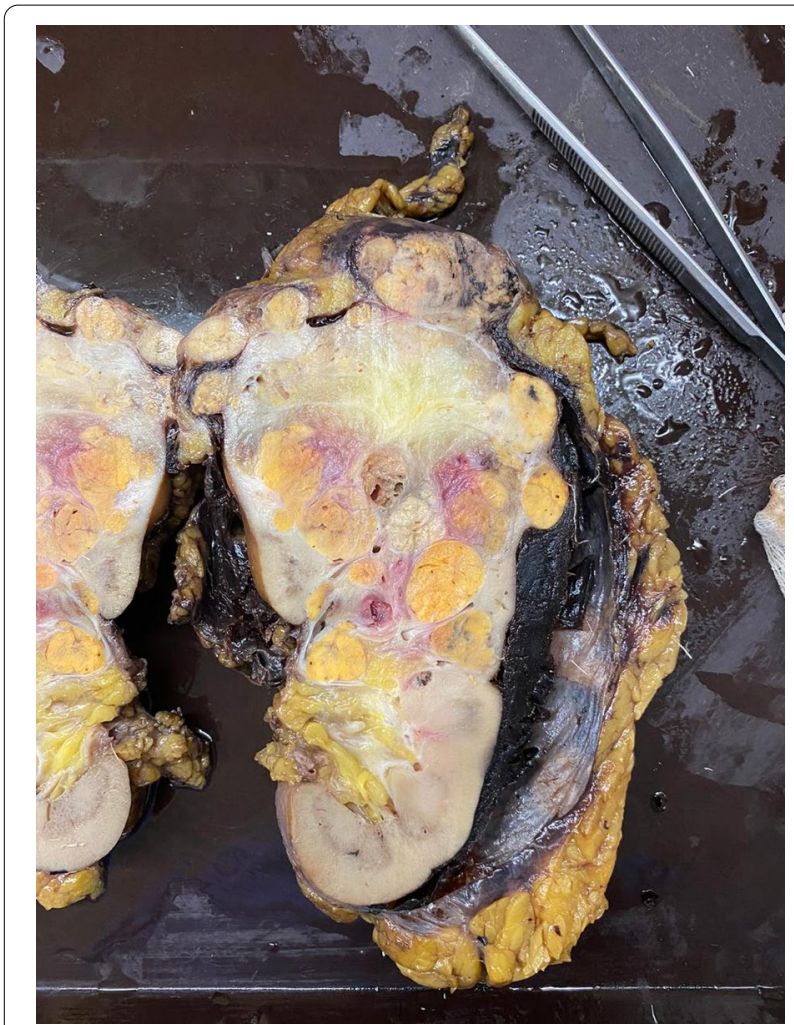

Fig. 3 Left kidney surgical piece that measures $160 \times 100 \times 75$ mm, in the upper pole and mid-region solid multinodular lesion

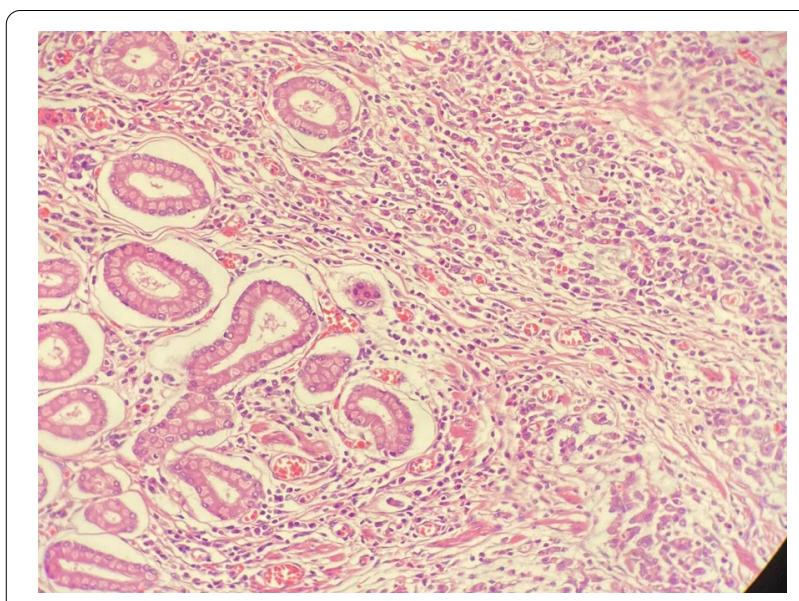

Fig. 4 GC. Histopathological examination of antrum and pylorus (Hematoxylin and Eosin (H\&E) staining $x 40$ ). In the lamina propria, individual cells of medium size are observed, with moderate pleomorphism and some in a signet ring

abdominal pain, weight loss without apparent cause, and absence of upper/lower urinary tract symptoms in most of the cases.

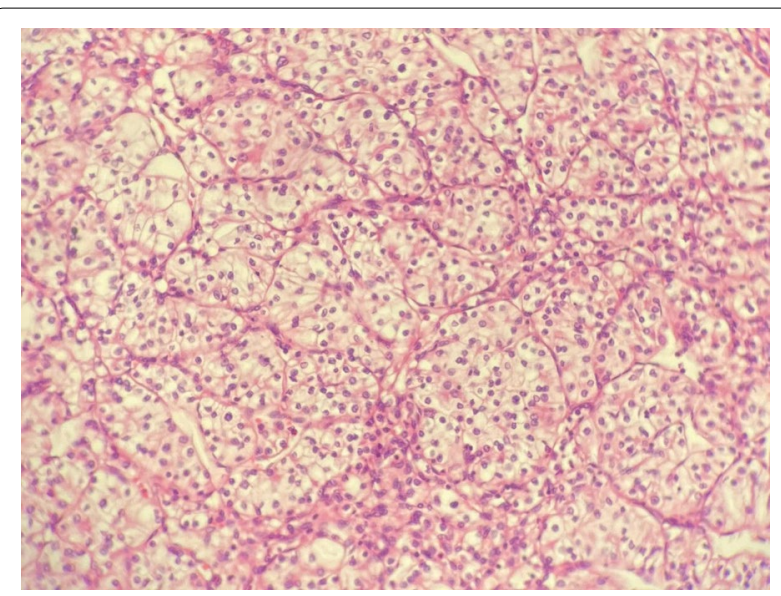

Fig. 5 RCC. Histopathological examination of the left kidney (H\&E $\times 20$ ) where large cell sheets with optically clear cytoplasm and round nuclei of fine chromatin are observed

Multiple combinations of surgical treatments are described, including partial gastrectomy/radical nephrectomy [5], subtotal gastrectomy/partial nephrectomy $[6,19]$, total gastrectomy/radical nephrectomy [17, 20], endoscopic gastric resection/radical nephrectomy [24], partial gastrectomy/total nephrectomy [17], mucosectomy/renal active surveillance [18], and total gastrectomy/renal active surveillance [22]. Among the surgical approaches for gastric cancer, partial gastrectomy was predominant, followed by total gastrectomy and subtotal gastrectomy. Two patients were diagnosed at an early stage, and conservative endoscopic approaches were adopted for treatment. With regard to the management of patients with renal carcinoma, multiple reviews revealed that radical nephrectomy was the most frequently performed surgical intervention, followed by total nephrectomy, partial nephrectomy, and two cases treated with active surveillance. Diagnostic renal carcinoma was more frequently on the left side with nephrectomy (partial, total, or radical) [5, 6, 19, 22-24].

Our review showed the prevalence of clinical stages in $\mathrm{GC}$, with stage IA being the most frequent, followed by stages IB, IIA, and IIIA [2, 6, 17, 20, 26]. On the other hand, stage II was the most frequent found for renal carcinoma $[6,20]$.

It was revealed that the most common histopathological findings of GC were described as poorly differentiated $[2,4,20]$, moderately differentiated $[19,22]$, and well differentiated $[17,26]$, in that order of presentation. The findings in the group of patients with renal carcinoma were cell carcinomas $[2,3,6,19,24]$ as the most frequent histopathological result, with other rare reported cases of chromophobe cell $[5,20,23]$ and transitional cell carcinoma [2]. 

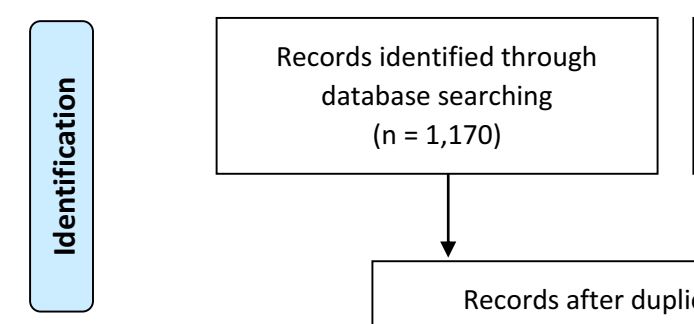

Additional records identified through other sources $(n=1,170)$

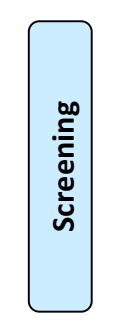

Records after duplicates removed

$(\mathrm{n}=1,080)$
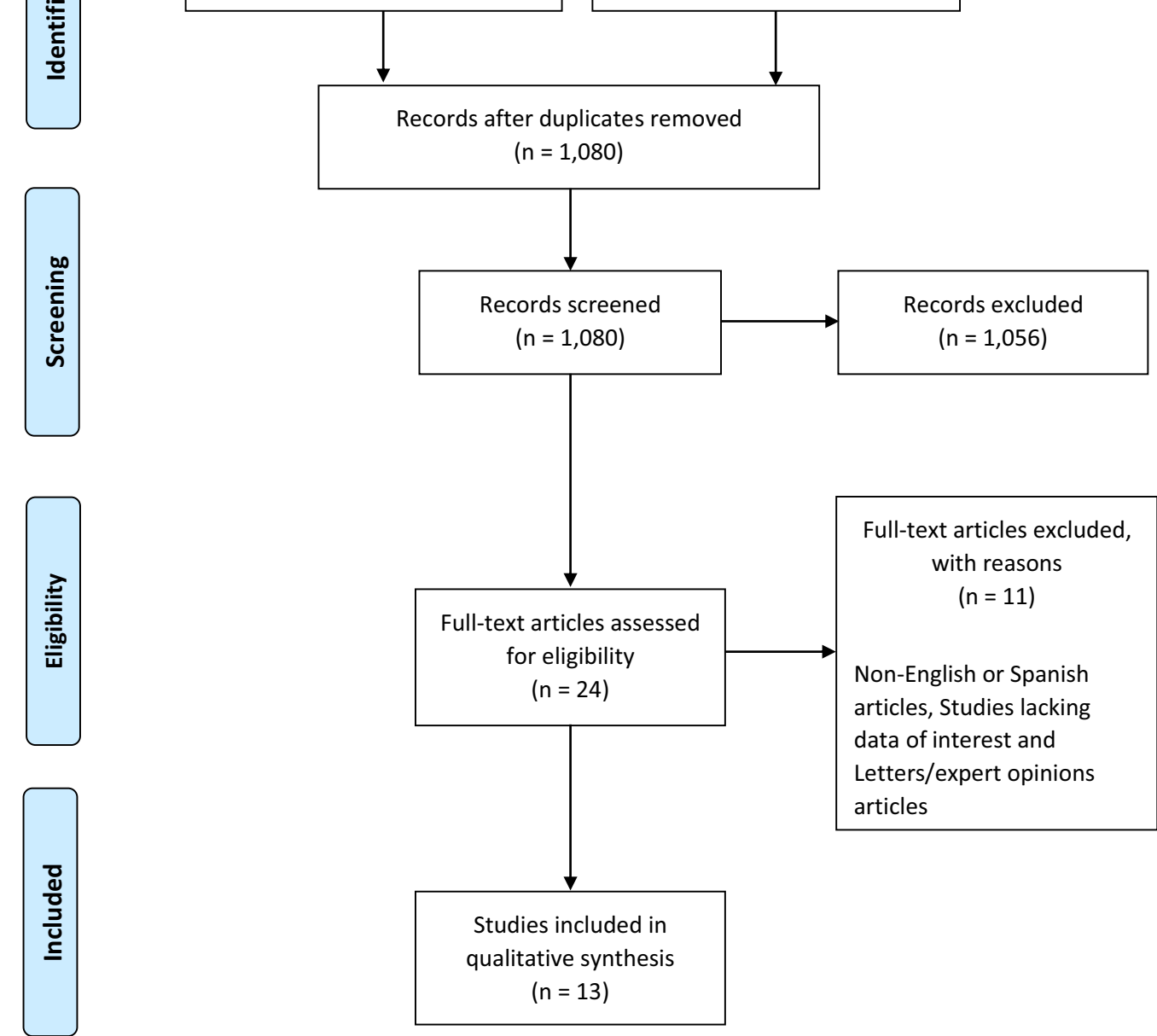

Fig. 6 PRISMA flow diagram detailing the search and identification strategy for the studies used in data synthesis

In addition, some cohort studies (presented in this review) $[2-4,17,18,23,24,26]$ revealed that survival and prognosis are improved in early clinical stage/grade and when both tumors were resected at the same surgical time.

The heterogeneous characteristics of the reviewed studies, the low number of relevant articles found, and the lack of specific studies in the literature limit the ability to make solid recommendations, and represent the main limitations of this systematic review.

\section{Discussion}

Gastric carcinoma (GC) is the second most frequent GI neoplasm worldwide, occupying fifth place in cancer mortality globally and representing $4 \%$ of cancer cases diagnosed in Mexico to 2018 [27].
The incidence of GC in presentation with another SPM varies from $0.7-11 \%[2,3,5,6,17-20,22,26]$. SPMs in relation to CG are most often tumors due to colorectal, lung, and liver cancer [14, 17-19, 28]. Synchronous renal cell carcinoma is very rare $(0.11-0.37 \%)$ finding in our review with an incidence of $0.10 \%$ and with a $2: 1$ male-female ratio. The incidence of synchronous cancer has been found to be higher in GC in early stage than in advanced stages (5.2\% versus $2.4 \%)[19,20]$.

The present study describes a rare case of a female patient in her seventh decade with a history of chronic smoking, presenting with nonspecific gastrointestinal symptoms and weight loss. During the diagnostic protocol, a left kidney tumor was found. She underwent surgery by partial gastrectomy with anastomosis and left radical nephrectomy. 


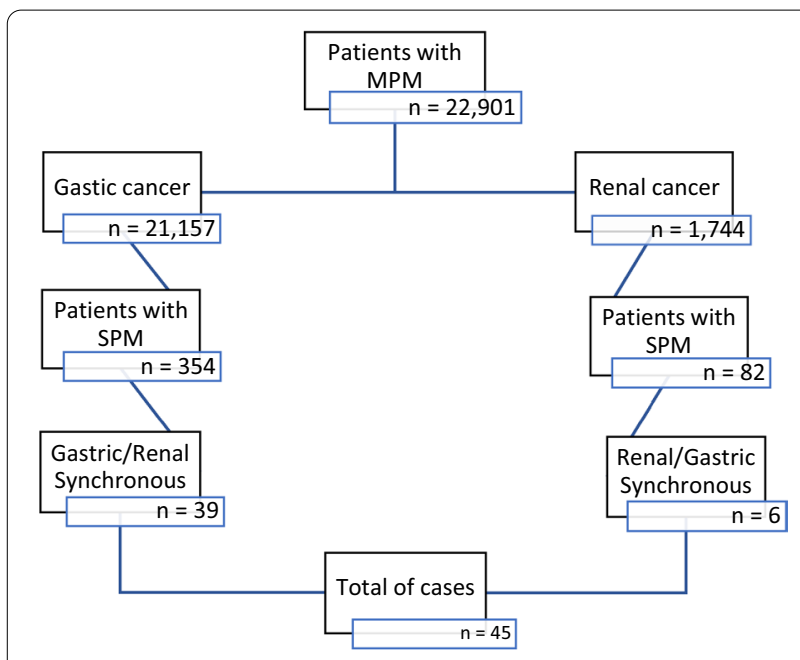

Fig. 7 Diagram explaining our total population and the result of gastric/renal synchronous cases

The most common presentation in patients seeking medical attention early is related to signs and symptoms associated with GC; the aforementioned is of utmost importance, since at the time of diagnosis they are usually in the early clinical stage, which makes it possible to carry out a comprehensive approach offering conservative and even curative treatments. However, early signs and symptoms are nonspecific, and include GI bleeding and nonspecific abdominal pain, accompanied by weight loss in up to $40 \%$ of patients over a period of $2-3$ months. For this reason, it is necessary to carry out, in all cases, a workup ranging from laboratory studies (including tumor markers), radiology (abdominal CT with contrast), and EGD with biopsies to rule out or confirm the diagnosis or other incidental findings.

In our review we found that the risk factors with the greatest impact were chronic smoking and advanced age (over 60 years) [2, 4, 17, 18, 20, 22-24, 29-31].
Males are more frequently affected, with a 2:1 male/ female relationship [32-35]. Another finding was that there is still no genetic alteration or association that links the synchronous presentation of both types of cancer, as noted by Betge et al. in their 2011 study, where they analyzed a group of patients with a welldifferentiated clear cell RCC presentation and aggressive and poorly differentiated gastric cancers. They were unable to associate a known hereditary cancer syndrome, and this will have to be explored in future studies [36].

The treatment most frequently reported in our review, and which coincides with that we carried out in the present study, was the resection of both primary tumors at the same surgical time; the most commonly performed technique was partial gastrectomy with anastomosis and radical nephrectomy, since it has been shown to have a better prognosis and longterm survival in patients [37]. It is worth noting that the involvement of the left kidney (87.5\%) was much more predominant than the right kidney in the articles included in our review [5, 6, 19, 22-24]. No cause or association can be concluded related to this finding.

Finally, survival is dependent on the primary tumor with the most advanced clinical stage, as this will determine the patient's prognosis and the appropriate management, ranging from chemotherapy to radiotherapy, and even including surveillance exams to rule out a recurrence or metastasis at a distant site or the possibility of a new tumor in another organ, since these patients are predisposed to the development of MPM [38-40]. Continuing with surveillance indefinitely is suggested in this group of patients due to the risk of recurrence.

We consider that the exclusion of studies written in a language other than English or Spanish could be considered a limitation, particularly due to the high prevalence in Asia.

Table 1 Studies with epidemiological design of reference centers

\begin{tabular}{|c|c|c|c|c|c|}
\hline Author & Country & Type of study & Population & $\begin{array}{l}\text { Synchronous } \\
\text { number of cases }\end{array}$ & $\begin{array}{l}\text { Number of synchronous } \\
\text { renal and gastric cases }\end{array}$ \\
\hline Ha et al. [17] & Korea & Retrospective cross-sectional & 10,090 & 90 & 11 \\
\hline Ławniczak et al. [18] & Poland & Retrospective cross-sectional & 862 & 23 & 1 \\
\hline Jiménez et al. [22] & Spain & Case series & 25 & 7 & 1 \\
\hline Bang et al.. [2] & Korea & Retrospective cohort & 4593 & 49 & 9 \\
\hline Lee et al.. [3] & Korea & Retrospective cross-sectional & 3291 & 115 & 5 \\
\hline Kim et al.. [4] & Korea & Retrospective cross-sectional & 41 & 17 & 3 \\
\hline Ikeda et al. [26] & Japan & Retrospective cohort & 2250 & 48 & 4 \\
\hline Beisland et al. [23]* & Norway & Retrospective cohort & 1425 & 53 & 2 \\
\hline Sato et al.. [24] ${ }^{*}$ & Japan & Retrospective cross-sectional & 319 & 29 & 4 \\
\hline
\end{tabular}

* Kidney tumor case studies 


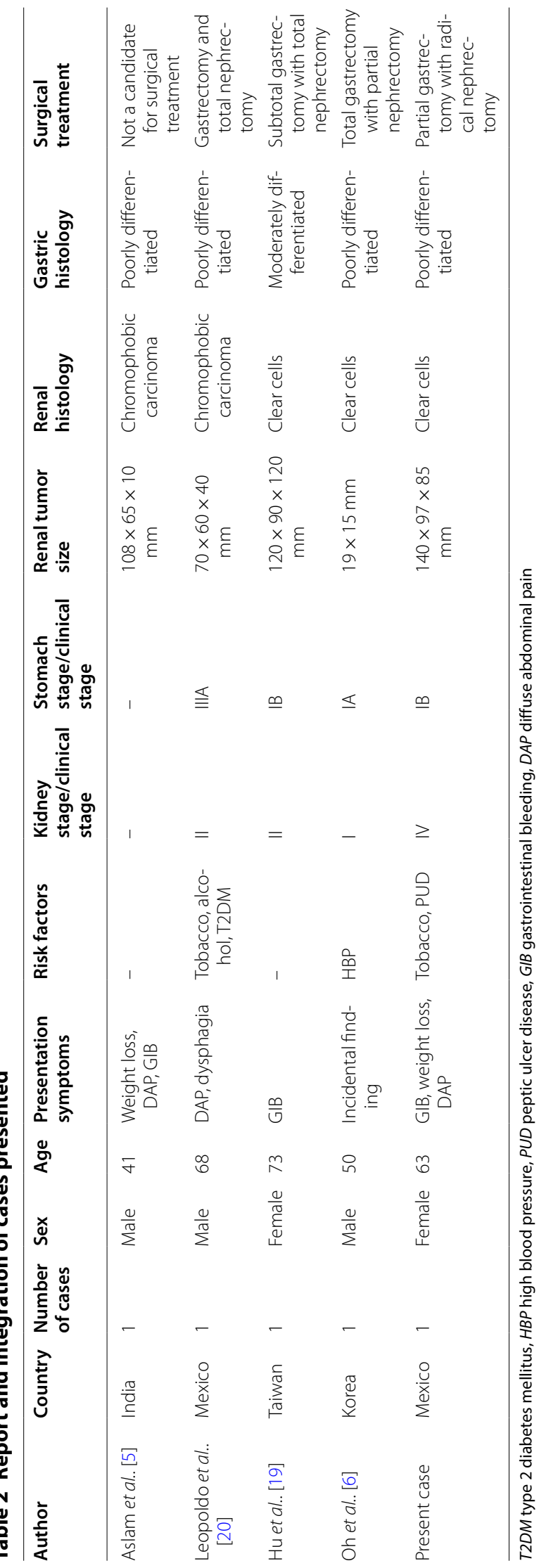




\section{Conclusion}

$\mathrm{GC}$ is the second leading carcinoma in the gastrointestinal tract. In addition, it is the neoplasm that is associated with second primary neoplasms. It can be recommended that patients older than 60 years with a history of smoking, and especially those of the male sex, be examined for a second primary neoplasm, with the aim of early diagnosis that can increase patient survival.

\begin{abstract}
Abbreviations
GC: Gastric carcinoma; SPM: Second primary malignancy; MPN: Multiple primary malignancies; PPI: Proton pump inhibitor; EGD: Esophagogastroduodenoscopy; PRISMA: Preferred Reporting Items for Systematic Reviews and Meta-Analyses; T2DM: Type 2 diabetes mellitus; HBP: High blood pressure; PUD: Peptic ulcer disease; GB: Gastrointestinal bleeding; DAP: Diffuse abdominal pain.
\end{abstract}

\section{Acknowledgements}

We thank the medical oncology and pathology departments of our institution for helping us with research and suggestions regarding genetic studies and in providing us with microscopic and macroscopic images of tumors.

\begin{abstract}
Authors' contributions
$J M, R T, D G, S S, C T$, and $K L$ were responsible for the study concept along with the study design. JM, JD, IDA, JN, and JG were responsible for data acquisition, data quality control and algorithms. IDA was in charge of the statistical analysis and interpretation of the data. JM, JD, IDA, JN, and JG prepared the manuscript; JM edited the manuscript; JM, RT, DG, SS, and CT revised the complete article. All authors read and approved the final manuscript.
\end{abstract}

\section{Funding}

No sources of funding were obtained for this project.

\section{Ethics approval and consent to participate}

This study was exempt from ethical approval at our institution, as it was an observational finding in regular practice.

\section{Consent for publication}

Written informed consent was obtained from the patient for publication of this case report and accompanying images. A copy of the written consent is available for review by the Editor-in-Chief of this journal on request.

\section{Competing interests}

The authors declare that they have no competing interests.

\section{Author details \\ 1 Surgical Department, "General Ignacio Zaragoza" Regional Hospital, Ejército Constitucionalista, Chinam Pac de Juárez, Calz. Ignacio Zaragoza 1711, 09220 Mexico City, MX, Mexico. ${ }^{2}$ Oncology Surgical Department, "General Ignacio Zaragoza" Regional Hospital, Mexico City, MX, Mexico. ${ }^{3}$ Pathology Department, "General Ignacio Zaragoza" Regional Hospital, Mexico City, MX, Mexico. ${ }^{4}$ Social Services and Security Institute for the State Employees (I.S.S.S.T.E.), Mexico City, MX, Mexico.}

Received: 14 September 2020 Accepted: 3 November 2020 Published online: 02 December 2020

\section{References}

1. WARREN, S. Multiple primary malignant tumors. A survey of the literature and a statistical study. Am J Cancer. 1932;16:1358-414. https:// ci.nii.ac.jp/naid/10005037946/en/. Accessed May 162020.
2. Bang WE, Lee HJ, Yoo MW, Jae JC, Woo HK, Yang HK, et al. Synchronous and metachronous cancers in patients with gastric cancer. J Surg Oncol. 2008;98(2):106-10.

3. Lee JH, Bae JS, Ryu KW, Lee JS, Park SR, Kim CG, et al. Gastric cancer patients at high-risk of having synchronous cancer. World J Gastroenterol. 2006;12(16):2588-92.

4. Kim JH, Rha SY, Kim C, Kim GM, Yoon SH, Kim KH, et al. Clinicopathologic features of metachronous or synchronous gastric cancer patients with three or more primary sites. Cancer Res Treat. 2010;42(4):217.

5. Aslam SSM, Sridhar H, Rao MY. A case of synchronous malignancy of stomach and kidney. Kathmandu Univ Med J. 2013;11(41):94-5.

6. Oh SJ, Bae DS, Suh BJ. Synchronous triple primary cancers occurring in the stomach, kidney, and thyroid. Ann Surg Treat Res. 2015;88(6):345-8.

7. Moertel CG. Multiple primary malignant neoplasms. Historical perspectives. Cancer. 1977;40(S4):1786-92. https://doi.org/10.1002/10970142(197710)40:4+\%3C1786::AID-CNCR2820400803\%3E3.0.CO.

8. de Martel C, Forman D, Plummer M. Gastric cancer. Epidemiology and risk factors. Gastroenterol Clin North Am. 2013;42(2):219-40. https://doi org/10.1016/j.gtc.2013.01.003.

9. Fang C, Huang Q, Lu L, Shi J, Sun Q, Xu GF, et al. Risk factors of early proximal gastric carcinoma in Chinese diagnosed using WHO criteria. J Dig Dis. 2015;16(6):327-36.

10. Hiyama T, Hanai A, Fujimoto I. Second primary cancer after diagnosis of stomach cancer in Osaka, Japan. Jpn J Cancer Res. 1991;82(7):762-70.

11. Amieva M, Peek RM. Pathobiology of Helicobacter pylori-induced gastric cancer. Gastroenterology. 2016;150(1):64-78. https://doi.org/10.1053/j. gastro.2015.09.004.

12. Burucoa C, Axon A. Epidemiology of Helicobacter pylori infection. Helicobacter. 2017;22:1-5.

13. Fischbach W, Malfertheiner P. Helicobacter Pylori infection. Dtsch Arztebl Int. 2018;115(25):429-36.

14. Lowenfels $A B$, Maisonneuve P. Associated primary tumors in patients with gastric cancer. J Clin Gastroenterol. 2002;34(5):501-2.

15. Young KP, Dong YK, Jae KJ, Jung CK, Yang SK, Seong YR, et al. Clinicopathological features of gastric carcinoma patients with other primary carcinomas. Langenbeck's Arch Surg. 2005;390(4):300-5.

16. Cheng HY, Chu CH, Chang WH, Hsu TC, Lin SC, Liu CC, et al. Clinical analysis of multiple primary malignancies in the digestive system: a hospitalbased study. World J Gastroenterol. 2005;11(27):4215-9.

17. Ha TK, An JY, Youn HG, Noh JH, Sohn TS, Kim S. Surgical outcome of synchronous second primary cancer in patients with gastric cancer. Yonsei Med J. 2007:48(6):981-7.

18. Ławniczak M, Gawin A, Jaroszewicz-Heigelmann H, Rogoza-Mateja W, Raszeja-Wyszomirska J, Białek A, et al. Synchronous and metachronous neoplasms in gastric cancer patients: A 23-year study. World J Gastroenterol. 2014;20(23):7480-7.

19. Hu KN, Lai WH, Tseng PT, Wang WC, Shen KH. Synchronous primary gastric cancer and renal cell carcinoma: A case report and literatures review. Urol Sci. 2012;23(1):28-30.

20. Leopoldo E, García M, Ahmed Y, Bezies N. Cáncer sincrónico, adenocarcinoma gástrico y cáncer de células renales. Actas Urológicas Españolas Julio. 2019;41(4):294-9.

21. Vrabel M. Preferred reporting items for systematic reviews and metaanalyses. Oncol Nurs Forum. 2015;42(5):552-4.

22. Jiménez AC, De Pierola LBF, Férez EO, Lasa IG, Andrés JB, Cadena JT, et al. Carcinoma gástrico asociado a otras neoplasias malignas primarias. Estudio retrospective de 25 casos. Rev Clin Esp. 2000;200(1):7-17. https:// doi.org/10.1016/S0014-2565(00)70543-1.

23. Beisland C, Talleraas O, Bakke A, Norstein J. Multiple primary malignancies in patients with renal cell carcinoma: A national population-based cohort study. BJU Int. 2006;97(4):698-702.

24. Sato S, Shinohara N, Suzuki S, Harabayashi T, Koyanagi T. Multiple primary malignancies in Japanese patients with renal cell carcinoma. Int J Urol. 2004;11(5):269-75.

25. Digaetano R, Purdue M, Rothman N, Wacholder S. Hypertension and risk of renal cell carcinoma. Epidemiology. 2011;22(6):797-804.

26. Ikeda Y, Saku M, Kawanaka H, Nonaka M, Yoshida K. Features of second primary cancer in patients with gastric cancer. Oncology. 2003;65(2):113-7.

27. Bray F, Ferlay J, Soerjomataram I, Siegel RL, Torre LA, Jemal A. Global cancer statistics 2018: GLOBOCAN estimates of incidence and 
mortality worldwide for 36 cancers in 185 countries. CA Cancer J Clin. 2018;68(6):394-424.

28. Kaibara N, Maeta M, Ikeguchi M. Patients with multiple primary gastric cancers tend to develop second primaries in organs other than the stomach. Surg Today. 1993;23(2):186-8.

29. Raei N, Behrouz B, Zahri S, Latifi-Navid S. Helicobacter pylori infection and dietary factors act synergistically to promote gastric cancer. Asian Pac J Cancer Prev. 2016;17(3):917-21.

30. Moyad MA. Review of potential risk factors for kidney (renal cell) cancer. Semin Urol Oncol. 2001;19(4):280-93.

31. Parsonnet J, Friedman GD, Vandersteen DP, Chang Y, Vogelman JH, Orentreich $\mathrm{N}$, et al. Helicobacter pylori infection and the risk of gastric carcinoma. N Engl J Med. 1991;325(16):1127-31.

32. Cote ML, Colt JS, Schwartz KL, Wacholder S, Ruterbusch JJ, Davis F, et al. Cigarette smoking and renal cell carcinoma risk among black and white Americans: effect Modification by Hypertension and Obesity. Cancer Epidemiol Biomarkers Prev. 2012;21(5):770-9.

33. Jacob L, Freyn M, Kalder M, Dinas K, Kostev K. Impact of tobacco smoking on the risk of developing 25 different cancers in the UK: a retrospective study of 422,010 patients followed for up to 30 years. Oncotarget. 2018;9(25):17420-9.

34. Chang YW, Singh KP. Duration-dependent effects of nicotine exposure on growth and AKT activation in human kidney epithelial cells. Mol Cell Biochem. 2018;448(1-2):51-60. https://doi.org/10.1007/s11010-018-3312-1.
35. Dhote R, Thiounn N, Debré B, Vidal-Trecan G. Risk factors for adult renal cell carcinoma. Urol Clin North Am. 2004;31 (2):237-47.

36. Betge J, Pollheimer MJ, Schlemmer A, Hoefler G, Langner C. Gastric cancer and concomitant renal cancer: a systematic immunohistochemical and molecular analysis. Oncol Rep. 2011;26(3):567-75.

37. Itoh H, Oohata Y, Nakamura K, Nagata T, Mibu R, Nakayama F. Complete ten-year postgastrectomy follow-up of early gastric cancer. Am J Surg. 1989;158(1):14-6.

38. Fujita T, Gotohda N, Takahashi S, Nakagohri T, Konishi M, Kinoshita T, Clinical and histopathological features of remnant gastric cancers, after gastrectomy for synchronous multiple gastric cancers. J Surg Oncol. 2009;100(6):466-71.

39. Ikeda Y, Saku M, Kishihara F, Maehara Y. Effective follow-up for recurrence or a primary cancer in patients with early gastric cancer. Br J Surg. 2005;92(2):235-9.

40. Yamamoto M, Yamanaka T, Baba H, Kakeji Y, Maehara Y. The postoperative recurrence and the occurrence of second primary carcinomas in patients with early gastric carcinoma. J Surg Oncol. 2008;97(3):231-5.

\section{Publisher's Note}

Springer Nature remains neutral with regard to jurisdictional claims in published maps and institutional affiliations.
Ready to submit your research? Choose BMC and benefit from:

- fast, convenient online submission

- thorough peer review by experienced researchers in your field

- rapid publication on acceptance

- support for research data, including large and complex data types

- gold Open Access which fosters wider collaboration and increased citations

- maximum visibility for your research: over 100M website views per year

At BMC, research is always in progress.

Learn more biomedcentral.com/submissions 